Research Article

\title{
Utilization pattern of oral hypoglycemic agents for diabetes mellitus type 2 patients attending out-patient department at tertiary care centre in Bhopal, Madhya Pradesh, India
}

\author{
Jambu Jain ${ }^{1}$, Parag Sharma ${ }^{1}$, Jigisha Jain ${ }^{2 *}$, Mustafa Raja ${ }^{1}$
}

\begin{abstract}
${ }^{1}$ Department of Pharmacology, L.N. Medical College, Bhopal, Madhya Pradesh, India

${ }^{2}$ Department of Pharmacology, Mansarovar Dental College, Bhopal, Madhya Pradesh, India
\end{abstract}

Received: 27 July 2016

Accepted: 08 August 2016

*Correspondence to:

Dr. Jigisha Jain,

Email: jigishajain31387@

gmail.com

Copyright: @ (the author(s), publisher and licensee Medip Academy. This is an openaccess article distributed under the terms of the Creative Commons Attribution NonCommercial License, which permits unrestricted noncommercial use, distribution, and reproduction in any medium, provided the original work is properly cited.

\begin{abstract}
Background: Diabetes mellitus type 2 is a chronic disease that may be due to insulin deficiency and insulin resistance or both. The resultant hyperglycemia leading to micro and macro vascular complications. The objective was to evaluate drug utilization pattern of oral hypoglycemic agents in type- 2 diabetic attending OPD.

Methods: A prospective study was carried out in 200 out patients for a period of 3 months in a tertiary care hospital. Patients treated with oral hypoglycemic agents were taken for the study.

Results: In the present study $102(51 \%)$ were male. Majority $(40 \%)$ of patient were in the age group 50-60 years. Metformin was the most commonly prescribed drug (38.3\%), followed by sulfonylurea class of drugs $(35.6 \%)$. Majority of the patients $n=143(71.5 \%)$ were on combination therapy in comparision to monotherapy $(28.5 \%)$. Fixed dose combinations more preferred more. Brand name was prefered $(98.1 \%)$ on generic drugs. Comorbid condition was found in 117 patients $(58.5 \%)$. And hypertension $(34 \%)$ was the the most common comorbid condition. The average number of antidiabetic drugs per prescription was 2.2 .

Conclusions: Metformin was the most commonly used drug .The prescribing trend also appears to be more towards combination therapy. It was seen that particularly two drug were used.
\end{abstract}

Keywords: Drug utilization, Oral hypoglycaemic drugs, Sulfonylurea, Monotherapy, Metformin

\section{INTRODUCTION}

Diabetes mellitus type 2 is a chronic disease that may be due to insulin deficiency and insulin resistance or both. The resultant hyperglycemia leading to micro and macro vascular complications and altered metabolism of lipids, carbohydrates, protein as well as an increased risk of vascular disease. ${ }^{1-6}$ Type 2 diabetes is much more common and accounts for around $90 \%$ of all diabetes cases worldwide. It occurs most frequently in adults but incidence is increasing in adolescents as well. ${ }^{6,7}$ In 2015 the number of people with diabetes in the world was 415 million, as per International Diabetes Federation (IDF), which is going to increase to almost 642 million by 2040 .
India is emerging as a country with a large number of people suffering from diabetes. According to IDF, 69.1 million of adults in India suffered from diabetes in the year $2015 .^{8}$ It has been predicted that the prevalence of diabetes in the adult population in India will be $6 \%$ by the year $2025 .^{9}$

Modern principles of management of diabetes focus on disease prevention, screening of high risk individuals and aggressive treatment of individuals in the pre-diabetic state. The current pharmacotherapy of diabetes mellitus includes treatment with drugs such as insulin and oral hypoglycaemic agents. Various oral hypoglycaemic agents differ in their modes of action, safety profiles and 
tolerability. Main drugs differ in the mechanism of action as sulfonylureas and rapidly acting secretagogues stimulate insulin secretion, biguanides reduce hepatic glucose production, $\alpha$-glucosidase inhibitors delay digestion and absorption of intestinal carbohydrate, thiazolidinediones improve insulin action and incretin based therapies like dipeptidyl peptidase-4 inhibitors boosts postprndial insulin release and lowers mealtime as well as fasting blood glucose in type 2 diabetics. ${ }^{10-12}$

According to World Health Organization, drug utilization is defined as the marketing, distribution, prescription and use of drugs in a society with special emphasis on the resulting medical, social and economic consequences. ${ }^{13}$

This kind of research in diabetes mellitus (DM) will provide useful insights into the different therapeutic traditions, reflect disease prevalence and data can be linked to adopt measures for decreasing morbidity and also to explore efficacy and toxicity of different therapies. $^{14-16}$

Therefore, drug utilization studies, which evaluate and analyze drug therapy are more meaningful, and observe the prescribing attitude of physicians with the aim to treat patient in a rational manner. Keeping all these facts in consideration, the present study was designed to analyze the prescribing patterns of oral hypoglycaemic drugs at L.N. Medical College and associated JK hospital, Bhopal, India.

\section{METHODS}

It was a prospective, observational and non-comparative study conducted at Medicine OPD in L.N. Medical College Bhopal, India. The present study was carried out in 200 established type 2 diabetes patients, who visited the hospital for treatment during the time period of January 2016 to April 2016. The study protocol was approved by institutional ethics committee.

\section{Inclusion criteria}

Type 2 diabetes mellitus patients, irrespective of age and sex, who were prescribed at least one oral hypoglycemic drug (OHD).

\section{Exclusion criteria}

Diagnosed diabetic patients who do not receive pharmacological therapy, unable to reply verbal questions as well as mentally retarded and unconscious patients; patients with any malignancy; pregnant and lactating females.

\section{RESULTS}

A total of 200 diabetic patients were evaluated during the study period. Out of these patients 102 were male and 98 were female.
Majority of our patients were in the age group of 51-60 years $(40 \%)$, followed by $62(31 \%), 28(14 \%)$ in the age group 61-70 and 41-50 respectively. Familial association with type 2 diabetes was seen in 36 (18\%) of the patients. Male patients $(n=20,55.6 \%)$ have shown more family history of diabetes mellitus than female patients $(n=16$, $44.4 \%$ ).

During the study period, a total of 443 OHDs were prescribed to the patients. The average number of OHDs prescribed per prescription were found to be 2.2. Biguanides $(n=170,38.3 \%)$ were the most commonly prescribed class, followed by sulphonylureas $(n=158$, $35.6 \%)$, thiazolidinediones $(\mathrm{n}=88,19.8 \%)$ and alphaglucosidase inhibitors $(\mathrm{n}=27,6 \%)$.

Table 1: Gender wise distribution of patients.

\begin{tabular}{|lll|}
\hline \hline Gender & Number of patient & Percentage \\
\hline Male & 102 & 51 \\
\hline female & 98 & 49 \\
\hline
\end{tabular}

Table 2: Age wise distribution of patients.

\begin{tabular}{|lll|}
\hline Age (years) & Number of patients & Percentage \\
\hline $18-30$ & 4 & 2 \\
\hline $31-40$ & 9 & 4.5 \\
\hline $41-50$ & 28 & 14 \\
\hline $51-60$ & 80 & 40 \\
\hline $61-70$ & 62 & 31 \\
\hline $71-80$ & 17 & 8.5 \\
\hline
\end{tabular}

Among individual medicines, metformin $(n=170,38.3 \%)$ was the most frequently prescribed OHDs, followed by glimepiride $(\mathrm{n}=97,21.89 \%)$ followed by pioglitazone $(n=88,19.8 \%)$, and gliclazide $(n=51,11.5 \%)$ (Table 3$)$.

A significant number of patients were prescribed combination therapy $(\mathrm{n}=143,71.5 \%)$ as compared to monotherapy $(n=57,28.5 \%), p<0.0001$. Fixed dose combination $(n=257,58.01 \%)$ were more preferred over individual medicine $(\mathrm{n}=187,42.2 \%)$ which was extremely significant $(\mathrm{p}<0.0001)$. The patients were treated with one $(n=57,28.5 \%)$, two $(n=74,37 \%)$, three $(n=51$, $25.5 \%)$, four $(n=16,8 \%)$ and five $(n=2,1 \%)$ OHDs.

Drug duplication was observed in five prescriptions (two in 5 drug regimen and three in 4 drug regimen). Almost all the medicines $(n=435,98.1 \%)$ were prescribed by brand name, only a fraction by generic name $(n=8,1.8 \%)$. Upward dose change was observed in 13 (6.5\%).

A very high percentage $(58.5 \%)$ of diabetes patients were found to be comorbid ( $\mathrm{p}<0.0001$, extremely significant) with different types of diseases that included hypertension, (31\%), followed by myocardial infarction, ischemic heart disease and hypothyroidism (3.5\% each). 
Table 3: Types of oral hypoglycemic agents prescribed.

\begin{tabular}{|llll|}
\hline \multirow{5}{*}{ Class } & Drug & No. of patients prescribed & \% consumption \\
\cline { 2 - 4 } & Glimpiride & 99 & 22.3 \\
\cline { 2 - 4 } & Gliclazide & 51 & 11.5 \\
\cline { 2 - 4 } & Glibenclamide & 3 & 0.6 \\
\cline { 2 - 4 } & Glipizide & 7 & 1.5 \\
\hline Biguanides & Metformin & 170 & 38.3 \\
\hline Thiazolidinediones & Pioglitazones & 88 & 19.5 \\
\hline \multirow{2}{*}{ Alpha glucosidase inhibitor } & Acarbose & 15 & 3.3 \\
\cline { 2 - 4 } & Voglibose & 12 & 2.7 \\
\hline Grand total & & 443 & 100 \\
\hline
\end{tabular}

Table4: Diabetes patient and associated concomitant disease.

\begin{tabular}{|lll|}
\hline $\begin{array}{l}\text { Diabetes with co morbid } \\
\text { conditions }\end{array}$ & $\begin{array}{l}\text { Number of } \\
\text { disease cases }\end{array}$ & $\begin{array}{l}\text { \% of } \\
\text { disease } \\
\text { cases }\end{array}$ \\
\hline $\begin{array}{l}\text { Diabetes } \\
\text { mellitus+hypertension }\end{array}$ & 68 & 34 \\
\hline $\begin{array}{l}\text { Diabetes } \\
\text { mellitus+myocardial } \\
\text { infarction }\end{array}$ & 10 & 5 \\
\hline Diabetes mellitus+gout & 2 & 1 \\
\hline $\begin{array}{l}\text { Diabetes } \\
\text { mellitus+congestive heart } \\
\text { failure }\end{array}$ & 5 & 2.5 \\
\hline $\begin{array}{l}\text { Diabetes mellitus+ischemic } \\
\text { heart disease }\end{array}$ & 13 & 6.5 \\
\hline Diabetes mellitus+asthma & 5 & 2.5 \\
\hline $\begin{array}{l}\text { Diabetes } \\
\text { mellitus+hypothyroidism }\end{array}$ & 7 & 3.5 \\
\hline $\begin{array}{l}\text { Diabetes mellitus+diabetic } \\
\text { retinopathy }\end{array}$ & 3 & 1.5 \\
\hline $\begin{array}{l}\text { Diabetes mellitus+diabetic } \\
\text { foot }\end{array}$ & 2 & 1 \\
\hline Diabetes mellitus+gastritis & 2 & 117 \\
\hline Total & & \\
\hline
\end{tabular}

\section{DISCUSSION}

In the present study, neither male nor female preponderance was seen (males $51 \%$, females $49 \%$ ) (Table 1). Similar results were obtained in other studies conducted in Kerala and Ahmedabad. ${ }^{17,18}$ However, the results are in contrast to a few studies conducted in India and other countries which have reported either male or female preponderance. ${ }^{19-23}$

Majority of our patients were in the age group of 51-60 years $(40 \%)$ which is in concordance with the earlier published literature. ${ }^{17,19,21,24}$ The mean age of the patients in the present study was 57.6 years (age range: 18-79 years) which is similar to that obtained in studies conducted in Nepal and Ahmedabad in which the mean age of patients was 56.9 and 56.8 years respectively. ${ }^{19,22}$
However, a study from Tenali, Andhra Pradesh reported the mean age of patients as 53.4 years. ${ }^{24}$

The mean number of OHDs per prescription was found to be 2.2 , which is higher than the number reported by Sutharson et al, and lower than the previous records of 2.99 from Hong Kong. ${ }^{25}$ In the present study metformin (biguanide) consumption was high (38.3\%), followed by sulfonylureas $(35.6 \%)$. Das et al, reported biguanides (24.5\%) and sulphonylureas (19.9\%) as the most commonly prescribed OHDs. ${ }^{26}$ Desai et al, reported the proportion of newly diagnosed patients initially treated with metformin increased from $51 \%$ to $65 \%$, whereas those receiving sulfonylureas decreased from $26 \%$ to $18 \% .{ }^{27}$ Boccuzzi et al, reported consumption of sulphonylureas that of $66.4 \%$ and metformin $24.3 \% .^{14} \mathrm{~A}$ study from Taiwan reported sulfonylureas as the most commonly prescribed drug class followed by biguanides. $^{28}$

Metformin is the therapy of choice for overweight and obese patients with type 2 diabetes. ${ }^{29}$ Metformin acts as a peripheral sensitizer of insulin and also has beneficial effects on insulin resistance, an important factor in the pathogenesis of type 2 diabetes. It reduces cardiovascularrelated mortality rates more than sulfonylurea. ${ }^{30}$ Metformin is unlikely to cause severe hypoglycemia, because it does not stimulate insulin release. So the physicians may have preferred metformin over other OHDs.

A large number of patients $(71.5 \%)$ were prescribed combination therapy to control diabetes. Type 2 diabetes mellitus is a progressive metabolic disease which is difficult to control, so the physicians may have prescribed more combination medicines to control the blood glucose level in the type 2 diabetes patients. But to be on the cautious note, it may create problems in forms of drug duplication, chances of drug interaction and adverse drug reactions. A study reported improved glycemic control following the addition of sulfonylureas to metformin, but deterioration resumes as early as 6 months. ${ }^{31}$

It is recommended that only WHO approved fixed dose combination products should be prescribed. The use of hospital formulary as approved by a competent pharmacy 
and therapeutic committee is also recommended for rational use of medicines. Furthermore lifestyle modifications, inclusive of dietary modification, regular physical activity and weight reduction are indicated for

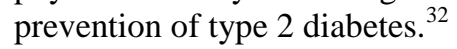

Change of dose and frequency was found to be an uncommon practice. Upward dosage change was observed in $6.5 \%$ of the study patients, which is remarkably less than the findings of Boccuzzi et al who reported 15\% $30 \%$ upward dosage changes. ${ }^{14}$

Inclination to brand name prescribing (98.1\%) was extremely significant $(\mathrm{p}<0.0001)$ in comparison to prescribing by generic names (1.8\%). In a recent Indian study from Allahabad, it was reported that only $2 \%$ of the medicines were prescribed by generic names. ${ }^{33}$ Upadhyay et al., reported $47.5 \%$ medicines prescribed by generic name in Nepal. ${ }^{19}$

This might be due to the absence of hospital formulary system and biased promotion of selected brands by the medical representatives of pharmaceutical manufacturers, which is a common practice in Indian hospitals. Prescribing by generic names should be promoted, as it could help in cheaper treatment to the patients which will reduce chance of drug duplication, drug interactions and adverse drug reactions as well as result in better compliance because treatment of diabetes is lifelong.

More than half of the study population was found to be co-morbid with various conditions. Hypertension was found to be most commonly associated disease (34\%) with diabetes, which is well corroborated with the findings of Bener et al who reported $29 \%$ hypertension as co-morbid in case of diabetics. ${ }^{34}$ These findings are significantly alarming, as hypertension is a predictor of cardiovascular disease.

\section{CONCLUSION}

Metformin was the most commonly used drug. The prescribing trend also appears to be moving towards combination therapy particularly two drug therapy. This study will contribute significantly to literature on drug utilization research. However, the study has its own limitations since follow-up of the patients was not possible and hence the effectiveness and tolerability profile of the anti-diabetic agents could not be assessed.

In the future one can investigate rationality of prescriptions, whether hospital formulary is followed or not as well as whether adherence to evidence based recommendations is seen or not.

Funding: No funding sources Conflict of interest: None declared

Ethical approval: The study was approved by the Institutional Ethics Committee

\section{REFERENCES}

1. Stratton IM, Adler AI, Neil HA, Matthews DR, Manley SE, Cull CA, et al. Association of glycemia with macrovascular and microvascular complications of type 2 diabetes (UKPDS 35): prospective observational study. British Med J. 2000;321:405-12.

2. Gerstein HC, Miller ME, Byington RP, Goff Jr DC, Bigger JT, Buse JB, et al. Effects of intensive glucose lowering in type 2 diabetes. New England J Med. 2008;358:2545-9.

3. Patel A, Macmahon S, Chalmers J, Neal B, Billot L, Woodward M, et al. Intensive blood glucose control and vascular outcomes in patients with type 2 diabetes. New England J Med. 2008;358:2560-72.

4. Raz I, Wilson PW, Strojek K, Kowalska I, Bozikov $\mathrm{V}$, Gitt AK, et al. Effects of prandial versus fasting glycaemia on cardiovascular outcomes in type 2 diabetes: the heart $2 \mathrm{~d}$ trial. Diabetes Care. 2009;32:381-6.

5. Davis SN, Granner DK. Insulin, oral hypoglycemic agents and the pharmacology endocrine pancreas. In: Hardman, J.G. and Limbird, L.E., Eds., Goodman and Gilman's Pharmacological Basis of Therapeutics. McGraw Hill, New York, 2001:15261531.

6. Campbell IW, Lebovitz H. Fast facts-diabetes mellitus; what is type 2 diabetes? $2^{\text {nd }}$ Edition, Health Press Ltd., Oxford. 2000:18-25.

7. Ahmann AJ, Riddle MC. Current oral agent for type 2 diabetes. Postgraduate Medicine. 2002;111:32-46.

8. IDF Diabetes Atlas. 7th ed. International Diabetes Federation, 2015. Available at: http://www.idf.org. Accessed on 14 March 2016.

9. King H, Aubert RE, Herman WH. Global burden of diabetes, 1995-2025: prevalence, numerical estimates, and projections. Diabetes Care. 1998;21(9):1414-31.

10. Unger J. Current strategies for evaluating, monitoring, and treating type 2 diabetes mellitus. Am J Med. 2008;121(6):3-8.

11. Krentz AJ, Bailey CJ. Oral antidiabetic agents: current role in type 2 diabetes mellitus. Drugs. 2005;65(3):385-411.

12. El-Kaissi S, Sherbeeni S. Pharmacological management of type 2 diabetes mellitus: An update. Curr Diabetes Rev 2011;7(6):392-405.

13. Lee D, Bergman U. Studies of drug utilization. In: Strom BL, editor. Pharmacoepidemiology. $4^{\text {th }}$ ed. New York: John Wiley and Sons;2005:401.

14. Boccuzzi SJ, Wogen J, Fox J, Sung JCY, Shah AB, Kim J. Utilization of oral hypoglycemic agents in a drug-insured U.S. population. Diabetes Care. 2001;24:1411-5.

15. Chan TYK, Lee KKC, Chan AWK, Critchley JAJH. Utilization of antidiabetic drugs in Hongkong: relation to the common occurrence of antidiabetic drug-induced hypoglycemia amongst acute medical 
admissions and the relative prevalence of NIDDM. Int J Clin Pharmacol Ther. 1996;34(1):43-6.

16. Niskanen L, Enlund H, Jormanainen V, Nissinen N, Uusitupa M. Therapeutic traditions in type 2 diabetes- are they changing? Eur J Clin Pharmacol. 1994;46(2):101-5.

17. Kannan, Arshad, Kumar S. A study on drug utilization of oral hypoglycemic agents in type-2 diabetic patients. Asian J Pharm Clin Res. 2011;4:60-4.

18. Dave DJ, Dikshit RK, Gandhi AM. Utilization of some newer oral antidiabetic agents in a tertiary care hospital. Natl J Physiol Pharm Pharmacol. 2012;2(2):146-51.

19. Upadhyay DK, Palaian S, Ravi Shankar P, Mishra P, Sah AK. Prescribing pattern in diabetic outpatients in a tertiary care teaching hospital in Nepal. J Clin Diagn Res. 2007;3:248-55.

20. Jimoh AO, Sabir AA, Chika A, Sani Z. Pattern of antidiabetic drugs use in a diabetic outpatient clinic of a tertiary health institution in Sokoto, Northwestern Nigeria. J Med Sci. 2011;11:241-5.

21. Vengurlekar S, Shukla P, Patidar P, Bafna R, Jain S. Prescribing pattern of antidiabetic drugs in Indore city hospital. Indian J Pharm Sci. 2008;70(5):63740.

22. Patel B, Oza B, Patel KP, Malhotra SD, Patel VJ. Pattern of antidiabetic drugs use in type 2 diabetic patients in a medicine outpatient clinic of a tertiary care teaching hospital. Int $\mathbf{J}$ Basic Clin Pharmacol. 2013;2:485-91

23. Sivasankari V, Manivannan E, Priyadarsini SP. Drug utilization pattern of anti-diabetic drugs in a rural area of Tamil Nadu, South India - a prospective, observational study. Int $\mathbf{J}$ Pharm Bio Sci. 2013;4:514-9.

24. Kumar KS, Sreeramya G, Krishna KM, Nalini K, Kiranmai N, Vasavi P. Drug use pattern study of antidiabetics in type 2 diabetes mellitus at a tertiary care hospital in Tenali, Andhra Pradesh. Int $\mathbf{J}$ Inv Pharm Sci. 2013;1:162-6.
25. Sutharson L, Hariharan RS, Vamsadhara C. Drug utilization in diabetology outpatient setting of a tertiary hospital. Indian J Pharmacol. 2003;35:23740.

26. Das P, Das BP, Rauniar GP, Roy RK, Sharma SK. Drug utilization pattern and effectiveness analysis in diabetes mellitus at a tertiary care centre in eastern Nepal. Indian Journal of Physiology and Pharmacology. 2011;55:272-80.

27. Desai NR, Shrank WH, Fischer MA, Avorn J, Liberman JN, Schneeweiss S, et al. Patterns of medication initiation in newly diagnosed diabetes mellitus: quality and cost implications. Am J Med. 2012;125:302-7.

28. Chiang CW, Chiu HF, Chen CY, Wu HL, Yang CY. Trends in the use of oral antidiabetic drugs by outpatients in Taiwan: 1997-2003. J Clinical Pharmacy Therap. 2006;31:73-82.

29. Cusi K, Defronzo RA. Metformin: a review of its metabolic effects. Diab Rev. 1998;6:89-131.

30. Johnson JA, Majumdar SR, Simpson SH, Toth EL. decreased mortality associated with the use of metformin compared with sulfonylurea monotherapy in type 2 diabetes. Diabetes Care. 2002;25:2244-8.

31. Cook MN, Girman CJ, Stein PP, Alexander CM, Holman RR. Glycemic control continues to deteriorate after sulfonylureas are added to metformin among patients with type 2 diabetes. Diabetes Care. 2005;28:995-1000.

32. Laakso M, Letho S. Epidemiology of macrovascular disease in diabetes. Diabetes Reviews. 1997;5:294315.

33. Ansari KU, Singh S, Pandey RC. Evaluation of prescribing pattern of doctors for rational medicine therapy. Indian J Pharmacology. 1998;30:43-6.

34. Bener A, Zirie M, Daghash MH, Alhamaq AO, Daradkeh AA, Rikabi A. Lipids, Lipoprotein (a) profile and hbalc among arabian type 2 diabetic patients. Biomedical Research. 2007;18:97-102.

Cite this article as: Jain J, Sharma P, Jain J, Raja M. Utilization pattern of oral hypoglycemic agents for diabetes mellitus type 2 patients attending out-patient department at tertiary care centre in Bhopal, Madhya Pradesh, India. Int J Basic Clin Pharmacol 2016;5:1826-30. 